\title{
Brain-Derived Neurotrophic Factor Enhances Long-Term Potentiation in Rat Visual Cortex
}

\author{
Yukio Akaneya, ${ }^{1}$ Tadaharu Tsumoto, ${ }^{1}$ Shuichiro Kinoshita, ${ }^{1}$ and Hiroshi Hatanaka ${ }^{2}$ \\ ${ }^{1}$ Department of Neurophysiology, Biomedical Research Center, Osaka University Medical School, Suita City, 565 Japan, \\ and ${ }^{2}$ Division of Protein Biosynthesis, Institute for Protein Research, Osaka University, Suita City, 565 Japan
}

Brain-derived neurotrophic factor (BDNF) and neurotrophin-3 (NT-3), members of the nerve growth factor (NGF) gene family, have been suggested to play a role in experience-dependent modification of neural networks in the developing nervous system. In this study we addressed the question of whether these neurotrophins are involved in long-term potentiation (LTP) in developing visual cortex. We recorded layer II/III field potentials and whole-cell currents evoked by test stimulation of layer IV at $0.1 \mathrm{~Hz}$ in visual cortical slices prepared from young rats (postnatal day 15-25) and observed effects of BDNF, NT-3, and NGF on these responses. Then we analyzed the effects of these neurotrophins on LTP induced by tetanic ( $\Theta$-burst type) stimulation of layer IV. We found that BDNF at $200 \mathrm{ng} / \mathrm{ml}$ potentiated field potentials and EPSCs in most cases and that this potentiation lasted after cessation of the BDNF application. At the concentration of $20 \mathrm{ng} / \mathrm{ml}$, BDNF did not show such an effect, but it enhanced the magnitude of expressed LTP. On the other hand, NT-3 and NGF had none of these effects. Immunohistochemical staining of slices with antibody against BDNF showed that exogenous BDNF penetrated into the whole slice within $\sim 5$ min of its application. The actions of BDNF were blocked by preincubation of slices with TrkB-IgG fusion protein, a BDNF scavenger, or coapplication of $\mathrm{K} 252 \mathrm{a}$, an inhibitor for receptor tyrosine kinases. TrkB-IgG or K252a itself completely blocked LTP, suggesting that endogenous BDNF or another TrkB ligand plays a role in LTP in the developing visual cortex.

Key words: brain-derived neurotrophic factor; long-term potentiation; nerve growth factor; neurotrophin-3; visual cortex; synaptic plasticity
Neurotrophins of the nerve growth factor (NGF) family have been considered to play roles in the differentiation, neurite outgrowth, and survival of developing neurons and maintenance of a certain group of matured neurons (Levi-Montalcini, 1987; Barde, 1989; Davies, 1994). In addition to these well known functions, accumulating evidence from recent studies suggests that the neurotrophins are involved in more rapid changes in the CNS and peripheral nervous system (Ip et al., 1993; Lohof et al., 1993; Kim et al., 1994; Le $\beta$ mann et al., 1994; Kang and Schuman, 1995; Levine et al., 1995; Wang et al., 1995; Stoop and Poo, 1996; Carmignoto et al., 1997; for reviews, see Bonhoeffer, 1996; Lewin and Barde, 1996). In particular, brain-derived neurotrophic factor (BDNF) is suggested to play a role in a form of synaptic plasticity, long-term potentiation (LTP), in the hippocampus (Castrén et al., 1992a; Patterson et al., 1992; Kang and Schuman, 1995; Figurov et al., 1996). Also, LTP in the hippocampus is reported to be impaired in BDNF knockout mice (Korte et al., 1995; Patterson et al., 1996)

In the developing visual cortex, it has been reported that the experience-dependent plasticity of structure and function of neural circuits is influenced by the neurotrophins, although the involvement of NGF is a matter of controversy (Maffei et al., 1992; Carmignoto et al., 1993; Cabelli et al., 1995; McAllister et al.,

Received April 23, 1997; revised June 20, 1997; accepted June 23, 1997.

This study is supported by a Grant-In-Aid for Scientific Research (07279102) from the Ministry of Education, Science, Sports and Culture of Japan. We express many thanks to Regeneron Pharmaceutical Co., Kyowa Hakko Kogyo Co., and Genentech Inc. for kind gifts of human recombinant BDNF, K252a, and TrkB-IgG, respectively. Correspondence should be addressed to Dr. Tadaharu Tsumoto, Department of Neurophysiology, Biomedical Research Center, Osaka University Medical School, Yamadaoka, Suita City, 565 Japan.

Copyright (C) 1997 Society for Neuroscience $0270-6474 / 97 / 176707-10 \$ 05.00 / 0$
1995, 1996; Riddle et al., 1995; Galuske et al., 1996; Hata et al., 1996). In addition, the expression of BDNF mRNA in the rat visual cortex was shown to decrease by visual deprivation (Castrén et al., 1992b; Bozzi et al., 1995; Schoups et al., 1995). In this area of the cortex LTP has been proposed as a synaptic basis for experience-dependent changes in structure and function of neural circuits (for reviews, see Tsumoto, 1992; Singer, 1995). Thus, a question arises about whether the neurotrophins are involved in LTP in the developing visual cortex. In the present study, therefore, we tested whether BDNF, NGF, and another neurotrophin, neurotrophin-3 (NT-3), have any effect on low-frequency synaptic transmission and LTP in layer II/III of visual cortical slices of young rats.

Part of the data in this study has been published previously in abstract form (Akaneya et al., 1996).

\section{MATERIALS AND METHODS}

Slice preparation. Sprague Dawley rats, aged from 15 to 25 postnatal days, were anesthetized deeply with ketamine $(30 \mathrm{mg} / \mathrm{kg}$, i.p.) (Sankyo, Tokyo, Japan) and then killed by cervical dislocation. Coronal slices of visual cortex (250-400 $\mu \mathrm{m}$ thickness) were cut using a rotor slicer (DTY7000, Dosaka, Kyoto, Japan). Procedures for maintaining the slices were essentially the same as those described previously (Kimura et al., 1989). In short, slices were submerged in a stream of the perfusion medium at the rate of $200 \mathrm{ml} / \mathrm{hr}$. The medium was aerated with $95 \% \mathrm{O}_{2} / 5 \% \mathrm{CO}_{2}$. The composition of incubation and perfusion medium of the slices was as follows (in mM): $124 \mathrm{NaCl}, 5 \mathrm{KCl}, 1.2 \mathrm{~K} \mathrm{H}_{2} \mathrm{PO}_{4}, 1.3 \mathrm{MgSO}_{4}, 2.4 \mathrm{CaCl}_{2}$, $26 \mathrm{NaHCO}_{3}$, and 10 glucose. All of the recordings were performed at $30-31^{\circ} \mathrm{C}$, unless noted otherwise.

Stimulation of afferents and recording of field potentials or synaptic currents. A bipolar stimulating electrode was placed in layer IV of the cortex. To record field potentials evoked by test stimulation of layer IV, glass micropipettes filled with $0.5 \mathrm{M}$ sodium acetate containing $2 \%$ pontamine sky blue (resistance $<10 \mathrm{M} \Omega$ ) were inserted into layer II/III 
of the cortex. Procedures for recording field potentials were conventional, as described previously (Kimura et al., 1989). In part of the experiments, EPSCs were recorded from pyramidal cell-like neurons in layer II/III of the cortex through whole-cell patch-clamp electrodes (Yoshimura and Tsumoto, 1994). These neurons were identified visually using an upright microscope with Nomarski optics (Axioscope FS, Zeiss, Germany). Whole-cell patch pipettes (resistance 4-8 M $\Omega$ ) were filled with a solution containing (in $\mathrm{mM}$ ): 130 potassium gluconate, $10 \mathrm{KCl}, 10$ HEPES, $3 \mathrm{MgATP}$, and $0.5 \mathrm{Na}_{2} \mathrm{GTP}$, and adjusted to $\mathrm{pH} 7.2$ by KOH. The osmolarity of the solution was $280-285$ mOsm. Visually identified neurons were voltage-clamped at $-70 \mathrm{mV}$ with a patch-clamp amplifier (Axopatch 200A or 200B, Axon Instruments). Membrane potentials were corrected for the liquid junctional potentials. The fast transient capacitive currents for recording electrodes were canceled, and the series resistance was compensated. The series resistance was $<20 \mathrm{M} \Omega$. Data were digitized at a rate of $10 \mathrm{kHz}$ and fed into an IBM-PC clone computer for analysis. Synaptic currents were filtered at 1 or $2 \mathrm{kHz}$. These data were analyzed mainly with pClamp software (Axon Instruments).

Test pulses of $0.1 \mathrm{msec}$ width were delivered at $0.1 \mathrm{~Hz}$, and the stimulus intensity was adjusted usually to 1.5 times the threshold to elicit the postsynaptic component of field responses. In the experiments in which EPSCs were recorded through patch pipettes, the stimulus intensity was 1.2-1.5 times the threshold for EPSCs. The intensity of test shocks was usually $2.5-4.0 \mathrm{~V}$ in field potential recordings and $1.0-2.0 \mathrm{~V}$ in whole-cell recordings.

Tests with the neurotrophins and blockers. After having confirmed that test shocks given to layer IV at $0.1 \mathrm{~Hz}$ induced constant responses for 10-20 min, human recombinant BDNF (Regeneron Pharmaceutical Co., Tarrytown, NY), human recombinant NGF (Boehringer Mannheim, Mannheim, Germany), human recombinant NT-3 (Promega, Madison, WI), or K252a (Kyowa Hakko Co., Tokyo, Japan) was applied to slices through the perfusion medium. In the experiments in which TrkB-IgG fusion protein (Genentech, San Francisco, CA) was tested, slices were preincubated in the medium containing this protein $(1 \mu \mathrm{g} / \mathrm{ml})$ for $2-4 \mathrm{hr}$. The neurotrophins were prepared at the concentration of $500 \mathrm{mg} / \mathrm{ml}$ containing $0.1 \%$ bovine serum albumin in undiluted $\mathrm{Ca}^{2+}-, \mathrm{Mg}^{2+}$-free PBS. They were diluted to 20,100 , or $200 \mathrm{ng} / \mathrm{ml}$ with the perfusion medium just before recordings. For application of K252a, this drug was prepared to be the final concentration of $200 \mathrm{~nm}$ with dimethyl sulfoxide as vehicle, of which the final concentration was $0.01 \%(\mathrm{v} / \mathrm{v})$. Inactivated $\mathrm{BDNF}$ was obtained by heating BDNF at $100^{\circ} \mathrm{C}$ for $5 \mathrm{~min}$. To prevent a possible adhesion of the neurotrophins to the wall of the perfusion system, the inner walls of the reservoir, recording chamber, and tubes connecting them were coated with silicone 2-3 d before recording.

To assess effects of BDNF, NT-3, NGF, and K252a, control responses to single shocks given to layer IV were recorded for 10-20 $\mathrm{min}$, and then the neurotrophins or K252a were applied to slices through the medium for 20 or $30 \mathrm{~min}$. Responses were further observed for $30 \mathrm{~min}$ after cessation of the application. To evaluate the effects quantitatively, the means of the peak-to-peak amplitude and rising slope of the postsynaptic component of field responses or those of the peak amplitude and falling slope of EPSCs for $10 \mathrm{~min}$ before the application were taken as control value. The slope was calculated using the value for $10-90 \%$ of the rising or falling phase of the responses. When an action of K252a on neurotrophin-induced effects was assessed, an application of K252a was started at least $10 \mathrm{~min}$ before the application of neurotrophins and continued until the end of recordings. In the tests with TrkB-IgG, it had been applied to slices before recordings. In these experiments, the mean value of the postsynaptic component of responses for $10 \mathrm{~min}$ before the neurotrophin application was taken as control. The statistical estimation for differences was performed with the Student's $t$ test or the one-way ANOVA followed by the Fisher's protected least significant difference multiple comparison post hoc analysis.

To determine the effects of the neurotrophins, TrkB-IgG, or K252a on LTP, tetanic stimulation was applied to layer IV. In the present study, we used the following type of tetanic stimulation: a brief, high-frequency pulse train $(4$ pulses at $100 \mathrm{~Hz})$ given at the $\Theta$-rhythm $(5 \mathrm{~Hz})$ for $2 \mathrm{sec}$ and repeated five times at $10 \mathrm{sec}$ intervals ( $\Theta$-burst tetanus). The width of each pulse was $0.2 \mathrm{msec}$, and its voltage was the same as that of test stimulation. In the experiments in which the neurotrophins or K252a were tested, control responses to single shocks given to layer IV were recorded for at least $10 \mathrm{~min}$, and then these substances were applied to slices through the medium. In this condition, responses to test stimulation were observed for $5 \mathrm{~min}$, and then tetanic stimulation was given to layer IV for $52 \mathrm{sec}$ at the $\Theta$-rhythm. After cessation of the tetanus, the neurotrophins or K252a continued to be applied for another 20 or 30 $\min$.

Immunohistochemical staining. Slices obtained 5 and $30 \mathrm{~min}$ after starting and also after stopping the application of BDNF at the concentration of 20 and $200 \mathrm{ng} / \mathrm{ml}$ and control slices before its application were fixed in $4 \%$ paraformaldehyde (Sigma, St. Louis, MO) for $1 \mathrm{hr}$, followed by overnight treatment with $30 \%$ sucrose in PBS. Then slices were frozen and sectioned at $40 \mu \mathrm{m}$ obliquely to the pial surface for the deeper core of the slice to be exposed simultaneously with the superficial rims on the same plane of the section. Sectioned slices were washed with PBS, intermitted by washing with $50 \%$ ethanol. These sections were incubated with 20\% normal horse serum (Vector Laboratories, Burlingame, CA) in PBS at least for $3 \mathrm{hr}$. Subsequently, the sections were incubated with chicken polyclonal antibody against human BDNF (Promega) at a dilution of 1:5000 in PBS containing 5\% (v/v) goat serum (Funakoshi, Tokyo, Japan), $0.3 \%$ Triton-X (Sigma), and $0.05 \% \mathrm{NaN}_{3}$ for $3-4 \mathrm{~d}$ at $4^{\circ} \mathrm{C}$. The sections were incubated with $0.7 \mu \mathrm{g} / \mathrm{ml}$ biotinylated anti-chicken $\mathrm{IgG}$ (Vector) for $90 \mathrm{~min}$, followed by further treatment with avidin-biotin complex (Vector) for $60 \mathrm{~min}$ at room temperature. Positive reaction products were visualized with $0.02 \%$ (w/v) 3,3' -diaminobenzidine 4-HCl (Sigma) dissolved in $0.05 \mathrm{M}$ Tris-buffered saline containing $0.01 \%(\mathrm{v} / \mathrm{v})$ $\mathrm{H}_{2} \mathrm{O}_{2}$. Specificity of the anti-BDNF antibody was tested by substitution of normal chicken serum for the antibody or by omission of the antibody from the immunohistochemical procedures.

\section{RESULTS}

\section{Potentiation of synaptic currents by BDNF}

Whole-cell patch-clamp recordings were performed from pyramidal cell-like neurons in layer II/III of the visual cortex. To check possible changes in recording conditions and membrane properties of cells under observation, we continuously monitored series and input resistances. If these values changed by $>20 \%$, the recordings were stopped and the data were deleted. Of the 21 cells observed for longer than $50 \mathrm{~min}$, eight neurons satisfied these criteria during such long-lasting recordings. In these eight neurons, single shocks applied to layer IV of the cortex induced inward currents lasting for $53.6 \pm 7.6 \mathrm{msec}$ (SEM), with mean peak latencies of $7.5 \pm 0.6 \mathrm{msec}$ and decay time constants of $11.0 \pm 2.6 \mathrm{msec}$ at the membrane potential of $-70 \mathrm{mV}$. These currents were judged as monosynaptically evoked EPSCs on the basis of the published criteria, such as very short and constant latency and reversal potential near $0 \mathrm{mV}$ (Yoshimura and Tsumoto, 1994). After test shocks of layer IV were confirmed to elicit EPSCs in the stable condition for $10 \mathrm{~min}$, BDNF was applied to slices. As will be described later, tests with field potential recordings showed that BDNF at the concentration of $20 \mathrm{ng} / \mathrm{ml}$ did not significantly change responses evoked by layer IV stimulation at $0.1 \mathrm{~Hz}$. Therefore, we applied BDNF at the concentration of $200 \mathrm{ng} / \mathrm{ml}$ and found that it clearly enhanced EPSCs in most of the cells. Figure 1 shows an example of EPSCs and a time course of their amplitude and slope and of series resistance of the recording system before, during, and after the application of BDNF. The peak amplitude of EPSCs might be contaminated by inhibitory currents, so we also measured the initial slope of EPSCs. A few minutes after the BDNF application was initiated, the amplitude and slope of EPSCs began to increase gradually and attained the plateau value $\sim 20$ min later. Moreover, the enhancement of EPSCs lasted without decline for at least 30 min after cessation of the BDNF application. The fairly constant series resistance indicates that the recording condition was very stable (Fig. $1 D$ ). As shown in Figure $1 B, C$, the amplitude of EPSCs changed in the same way as the slope did, although the magnitude of change in the former value was slightly smaller than that in the latter. Such parallelism of the two measures was also seen in other cells. Subsequently, therefore, we measured the 
A
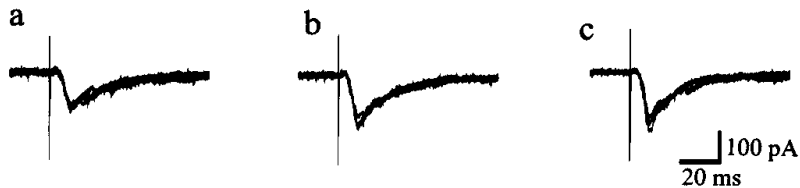

B

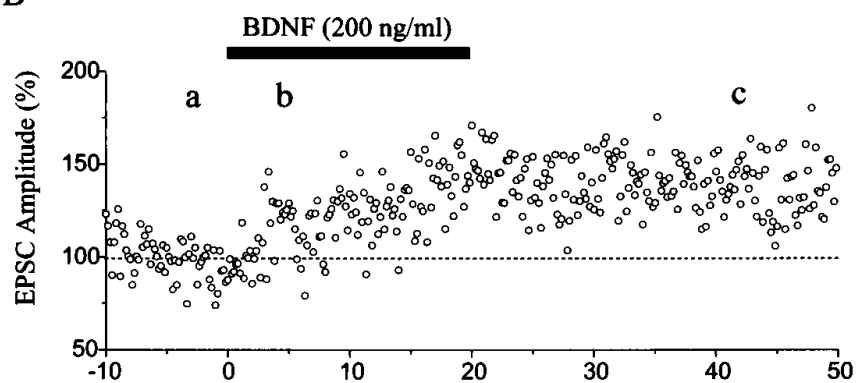

C

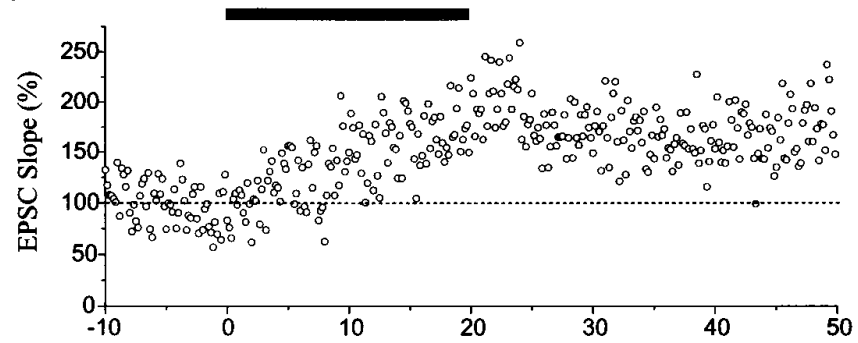

$\mathrm{D}$

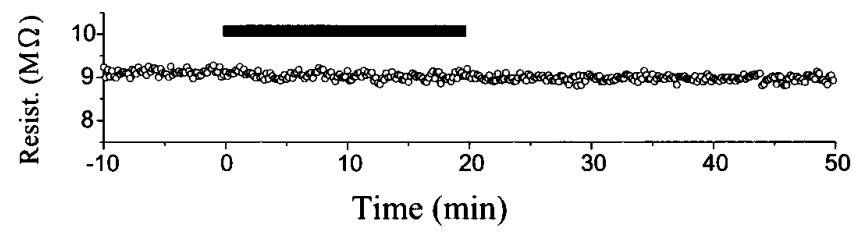

Figure 1. Potentiation of EPSCs by BDNF. A, Examples of EPSCs recorded from a pyramidal cell-like neuron in layer II/III of the cortex before $(a)$, during $(b)$, and after $(c)$ the application of BDNF. Test stimulation was given to layer IV at $0.1 \mathrm{~Hz}$. Membrane potential was clamped at $-70 \mathrm{mV}$. The time when each record was obtained is shown by corresponding letters in $B$ : superimposition of five sweeps. $B, C$, Plots of the peak amplitude and falling slope of EPSCs against time, respectively. The value is expressed as the percentage of the mean of 60 responses before the application of BDNF. $D$, Plots of the series resistance against time. The time when BDNF was applied to the slice is indicated by a horizontal bar.

peak amplitude of EPSCs to evaluate the effect of BDNF. In six of the eight cells, EPSCs were significantly (paired $t$ test; $p<$ 0.05 ) potentiated, as shown in Figure 4 (filled circles).

The stable recording of whole-cell synaptic currents for a long time is a time-consuming task that often wastes neurotrophins and their blockers because of interruption of recordings halfway. This is particularly problematic in the present study, in which we attempted to test the three kinds of neurotrophins and the two types of functional blockers. As reported previously and confirmed in the present study, the postsynaptic component of layer II/III field potentials corresponds to EPSPs or EPSCs recorded from layer II/III neurons (Kimura et al., 1989; Kirkwood et al., 1993). In fact, we observed that the postsynaptic component of field potentials changed in parallel with EPSCs after the application of BDNF (Figs. 1, 2). In the subsequent experiments, therefore, we measured the postsynaptic component of layer
A
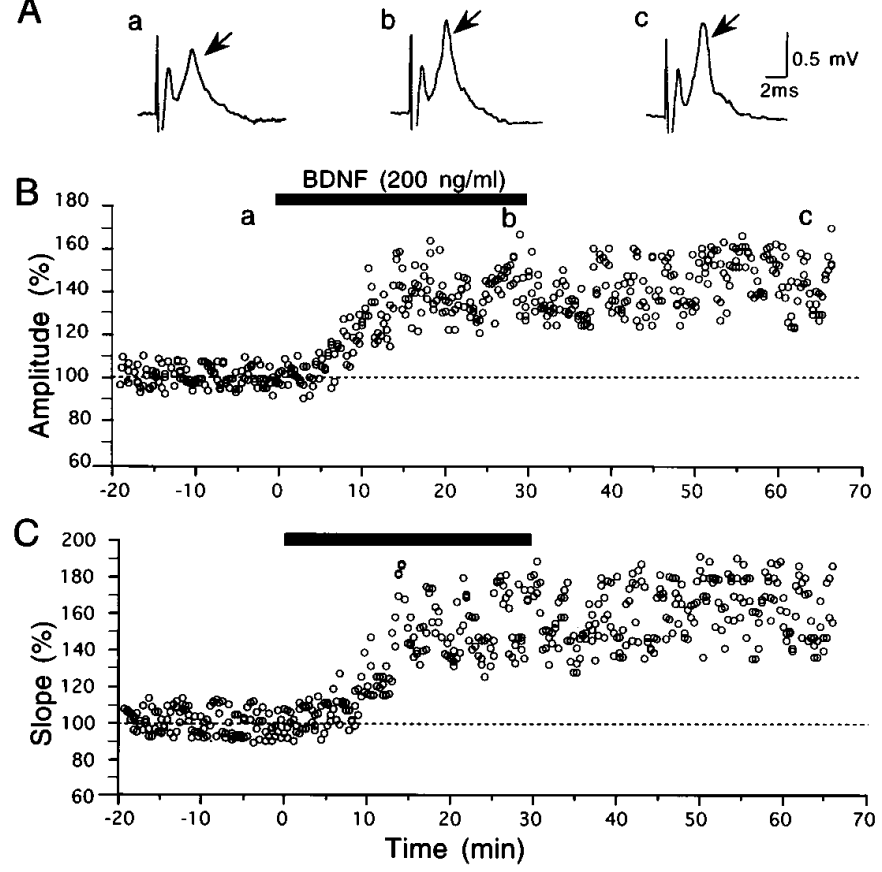

Figure 2. Potentiation of field responses by BDNF. $A$, Examples of field responses of layer II/III to test stimulation of layer IV, recorded at the time points indicated by corresponding letters in B. Arrows indicate the postsynaptic component of responses. Initial upward (negative) peaks are potentials evoked antidromically by layer IV stimulation. $B, C$, Plots of the amplitude and rising slope of the postsynaptic component of field potentials against time, respectively. BDNF at $200 \mathrm{ng} / \mathrm{ml}$ was applied to the slice during the period indicated by horizontal bar. In $B$, the amplitude of the postsynaptic component from the preceding positive (downward) to negative peak was measured and expressed as the percentage of the mean of 60 responses before the application of BDNF. In $C$, the slope of the rising phase (from 10 to $90 \%$ point) of the postsynaptic component was measured and expressed in the same way as in $B$.

II/III field potentials evoked by test stimulation of layer IV to assess actions of those substances on synaptic transmission in layer II/III of the visual cortex.

\section{Potentiation of field potentials by BDNF}

From layer II/III of the cortex, field responses consisting of two components were elicited by single shocks applied to layer IV of the cortex (Figs. 2A,6A), as reported previously (Kirkwood et al., 1993; Haruta et al., 1994). The initial and second components of responses were judged as antidromically and postsynaptically induced, because they were resistant and sensitive to the $\mathrm{Ca}^{2+}$ free solution, respectively.

After test shocks of layer IV were confirmed to elicit field responses with almost constant amplitude for 10-20 min, BDNF, NT-3, or NGF was applied to slices at a given concentration. Initially we applied BDNF at the concentration of $20 \mathrm{ng} / \mathrm{ml}$ for 20 or $30 \mathrm{~min}$. The application of BDNF at this concentration did not significantly change field responses evoked by layer IV stimulation at $0.1 \mathrm{~Hz}$, so we increased its concentration to $200 \mathrm{ng} / \mathrm{ml}$ and found that BDNF clearly enhanced field responses in most of the slices tested. Figure 2 shows an example of responses and a time course of the amplitude and slope of the postsynaptic component of responses before, during, and after the application of BDNF. Approximately $5 \mathrm{~min}$ after the BDNF application was initiated, the postsynaptic component began to increase gradually and attained the plateau value $\sim 10 \mathrm{~min}$ later. Moreover, the enhance- 
Figure 3. Time courses of the mean amplitude of field responses. For each slice, the mean of six consecutive responses was calculated as a percentage of that of 60 control responses before the application of BDNF. Vertical bars indicate twice the SEM. Circles without vertical bars indicate that the value of SEM was smaller than that of the radius. $A-D, \mathrm{BDNF}$ was applied to slices as indicated by horizontal bars. In $A$, the asterisk indicates that the number of slices during the marked period was six; otherwise the number of slices was 15 . In $B$, slices were preincubated with TrkB-IgG. The number of slices used for each test is shown at the top of each graph.

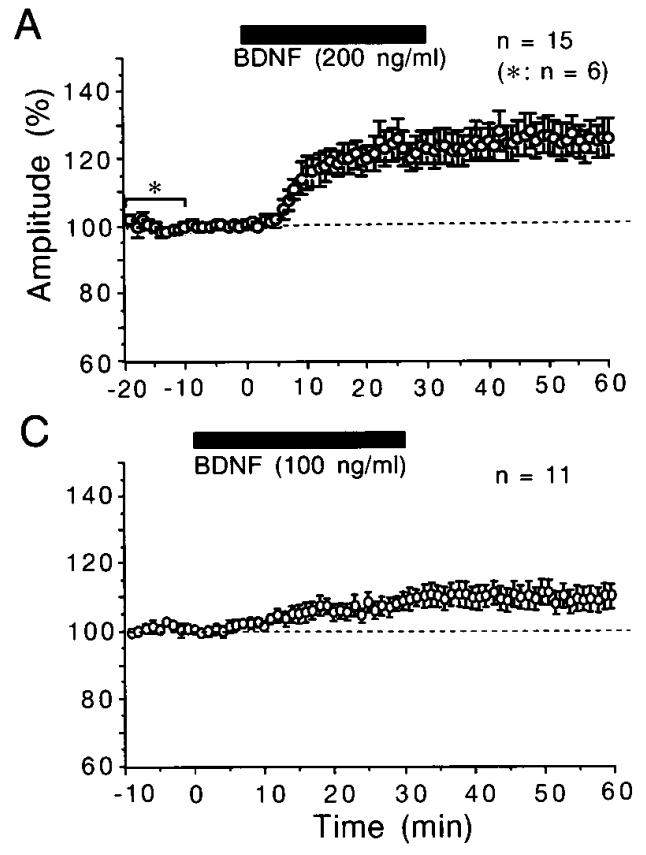

ment of the responses lasted without decline for at least $30 \mathrm{~min}$ after cessation of the BDNF application. As shown here, the peak-to-peak amplitude of the postsynaptic component of field potentials changed in parallel with the slope of its rising phase. Such a parallel change between the two measures was seen in other slices. In the present study, therefore, we measured the peak-to-peak amplitude of the postsynaptic component. The mean amplitudes for the 15 slices after the application time of 8 min were significantly (paired $t$ test; $p<0.05$ ) larger than those before its application (Fig. $3 A$ ). In six slices in which the control recording period preceding the BDNF application was $20 \mathrm{~min}$, the amplitude of the responses during the last 10 min was not different from that during the initial $10 \mathrm{~min}$. Therefore, the preapplication control period was set at $10 \mathrm{~min}$ in most cases. The enhancing effect of BDNF was not observed at the concentration of $20 \mathrm{ng} / \mathrm{ml}$, as mentioned above (Fig. 3D). The application of
$\mathrm{BDNF}$ at the concentration of $100 \mathrm{ng} / \mathrm{ml}$ showed a weak, but significant (paired $t$ test; $p<0.05$ ) augmentation of responses after the application time of $16 \mathrm{~min}$ (Fig. $3 C$ ). In the left three columns of Figure 4, the ratio of the field potential amplitude 25-30 min after starting the BDNF application to that before the application is plotted for each slice. The difference in the mean value between 20 and $200 \mathrm{ng} / \mathrm{ml}$ was statistically significant (unpaired $t$ test; $p<0.0005)$. These results indicate that BDNF enhances the efficacy of synaptic transmission in layer II/III of the visual cortex in a dose-dependent manner. Unlike BDNF, however, NT-3 and NGF at the concentration of $200 \mathrm{ng} / \mathrm{ml}$ had no effect on layer II/III responses to test stimulation of layer IV in the visual cortex (Fig. 4, second from right and far right columns).

We then examined the question of whether these actions of $\mathrm{BDNF}$ are mediated through tyrosine kinase receptors, because
Figure 4. Changes in response amplitude during neurotrophin application. The ordinate represents the ratio of the mean amplitude of field responses (open circles) calculated from 30 responses for 25-30 min or that of EPSCs ( filled circles) from 30 responses for 15-20 min after starting the neurotrophin application to that of 60 responses just before the application. Short horizontal bars and vertical bars represent means and twice the SEM for the same group of slices or cells, respectively. The number of slices or cells used for each test is shown at the top of each column.

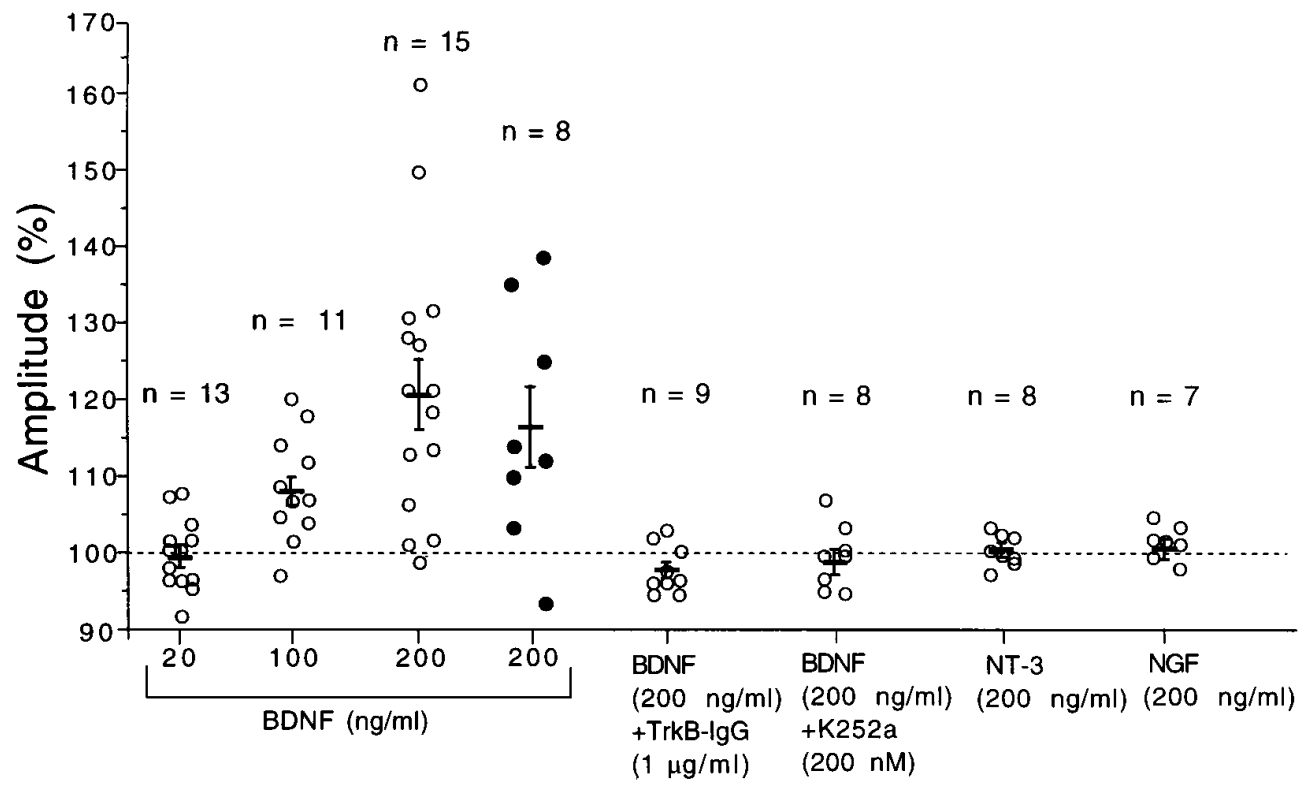


A

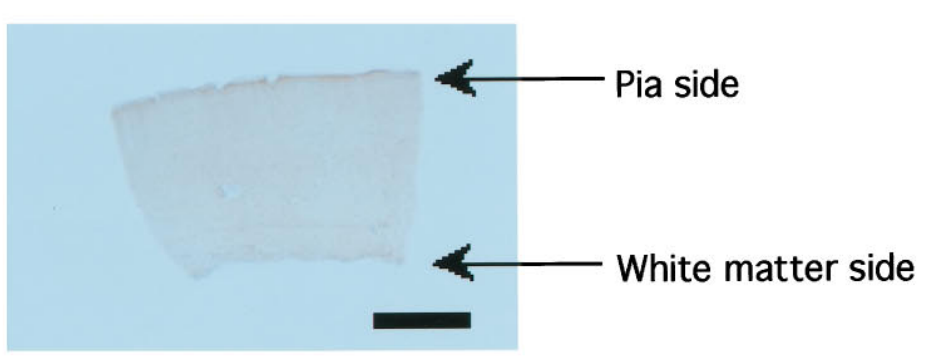

B

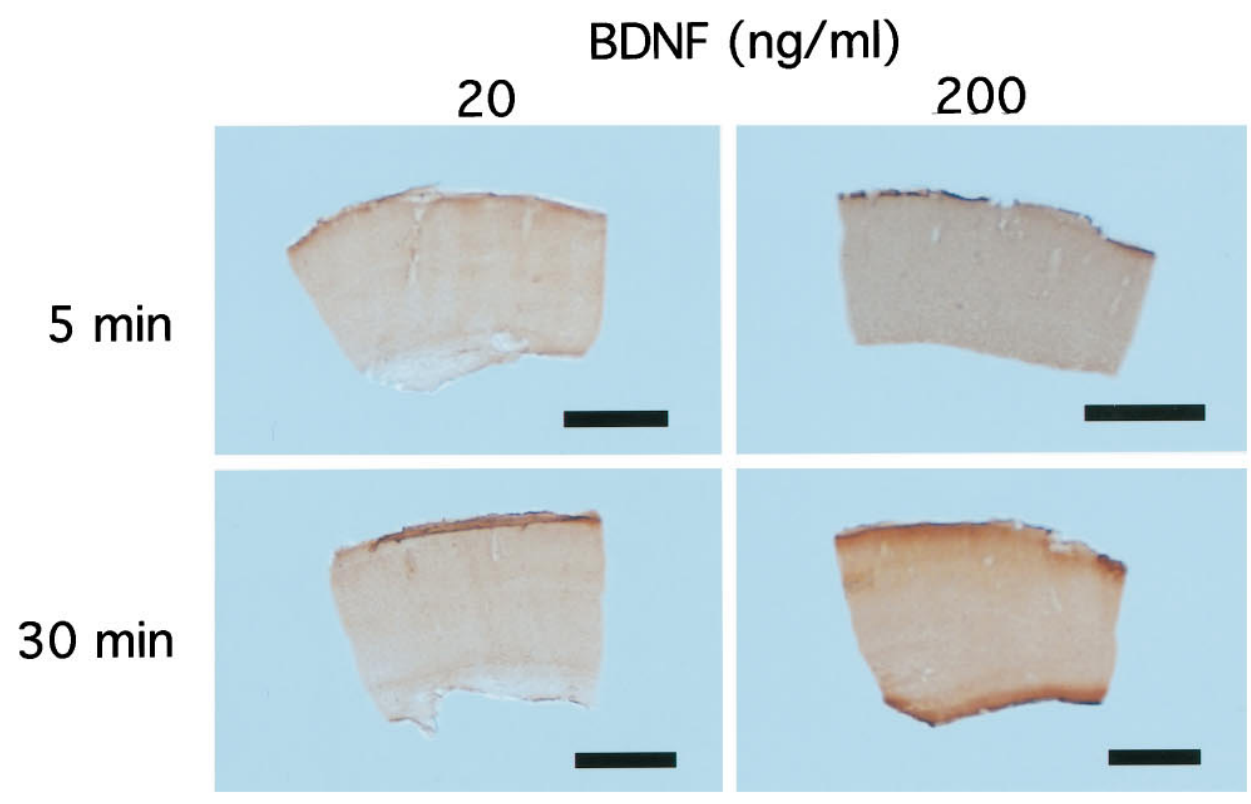

C

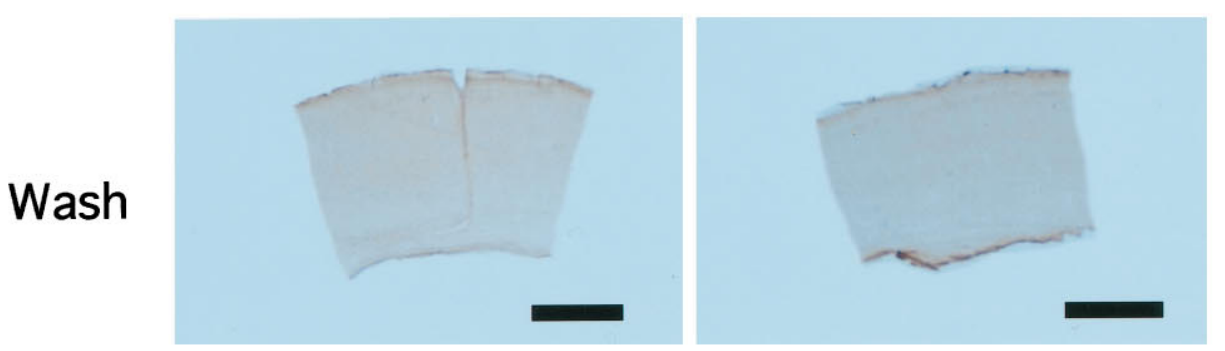

Figure 5. Rapid penetration of BDNF into slices. Photomicrographs of sections obtained from slices before $(A)$, during $(B)$, and after $(C)$ perfusion with the medium containing $\mathrm{BDNF}$ at the indicated concentration. Scale bars, $1 \mathrm{~mm}$. All of the slices shown here were processed simultaneously in identical staining conditions. Pia is upward and white matter is downward for each slice. In $C$, slices were subjected to immunohistochemistry $30 \mathrm{~min}$ after the medium containing BDNF at 20 (left) and 200 (right) $\mathrm{ng} / \mathrm{ml}$ was changed to the standard medium. biological actions of BDNF on neurons are known to be mediated via TrkB receptors (for reviews, see Bothwell, 1995; Thoenen, 1995). To test this question we used TrkB-IgG fusion protein, which competes with TrkB receptors for binding BDNF (Shelton et al., 1995), and K252a, which inhibits tyrosine kinase activity of Trk receptors (Kase et al., 1986; Koizumi et al., 1988; for review, see Knüsel and Hefti, 1992). We initially tested whether TrkBIgG or K252a itself has any effect on synaptic transmission at 0.1 $\mathrm{Hz}$ in layer II/III of the cortex. The preincubation with TrkB-IgG did not affect field potentials evoked by test stimulation of layer IV at $0.1 \mathrm{~Hz}$. The intensity of test shocks was set in the same range as in the recordings without TrkB-IgG. The mean amplitude of the postsynaptic component of field responses for the 41 slices that had been incubated with this protein was $0.70 \pm 0.03$
$\mathrm{mV}$ (SEM). This value was not significantly different from that $(0.77 \pm 0.02 \mathrm{mV})$ for the 149 slices without TrkB-IgG. Also, the application of $\mathrm{K} 252 \mathrm{a}$ at the concentration of $200 \mathrm{nM}$ did not significantly change field responses in any of the seven slices tested. The peak-to-peak amplitude of the postsynaptic component $30 \mathrm{~min}$ after starting its application was $98.2 \pm 2.5 \%$ (SEM) of the control. We then tested whether TrkB-IgG or K252a could block the potentiating effect of BDNF. In slices that had been preincubated with TrkB-IgG, BDNF at $200 \mathrm{ng} / \mathrm{ml}$ did not induce significant change in field potentials (Fig. 3B; also see Fig. 4, fifth column from left). In the experiments in which K252a was tested, it was coapplied with BDNF (200 ng/ml) and was found to block the potentiating effect of BDNF in seven of the eight slices (Fig. 4 , sixth column from left). These results suggest that the long- 
lasting enhancing effect of BDNF at $200 \mathrm{ng} / \mathrm{ml}$ on layer II/III responses may be mediated through TrkB receptors.

\section{Rapid penetration of BDNF into slices}

Because the action of BDNF was found to be relatively rapid, there was a question of how quickly BDNF, which was exogenously applied at the perfusion rate of $200 \mathrm{ml} / \mathrm{hr}$, penetrated into slices of the visual cortex. To examine this question, slices perfused with the medium containing BDNF at 20 or $200 \mathrm{ng} / \mathrm{ml}$ for 5 and $30 \mathrm{~min}$ and slices before and after the BDNF application were stained immunohistochemically with the antibody against BDNF. To minimize the possible difference in the intensity of reactivity attributable to staining procedures, all of the slices were processed simultaneously under identical conditions. After the perfusion of slices with BDNF at $20 \mathrm{ng} / \mathrm{ml}$ for $5 \mathrm{~min}$, the immunoreactivity against exogenous BDNF was clearly recognizable in the whole cortex (Fig. $5 B$, top left). This antibody did not recognize endogenous BDNF with the present staining procedures (Fig. 5A). After perfusion with $200 \mathrm{ng} / \mathrm{ml}$ of BDNF for $30 \mathrm{~min}$, the immunoreactivity of slices was more intense (Fig. $5 B$, bottom right). Five minutes after starting to wash out exogenous BDNF, the immunoreactivity became very faint (data not shown) and almost disappeared 25 min thereafter (Fig. $5 C$ ). The same series of immunostaining was repeated in five slices for each test, and essentially the same results as above were observed. This antibody against BDNF fulfilled the following specificity tests: no recognizable staining was observed in slices that had been perfused with BDNF at $200 \mathrm{ng} / \mathrm{ml}$ for $30 \mathrm{~min}$ when the antibody was replaced by normal chicken serum, or the antibody was omitted from the immunohistochemical procedures. These findings indicate that exogenous BDNF applied through the medium could penetrate into slices within $5 \mathrm{~min}$, under the present perfusion condition, and could be washed out substantially within another 5 min after the medium was changed to the standard one without BDNF. This suggests that the long-lasting potentiation of responses after cessation of the application may not be attributable to residues of exogenous BDNF in slices.

\section{Enhancement of LTP by BDNF at the lower concentration}

Although BDNF at the concentration of $20 \mathrm{ng} / \mathrm{ml}$ did not potentiate layer II/III field responses evoked by test stimulation of layer IV at $0.1 \mathrm{~Hz}$, it enhanced the magnitude of LTP induced by tetanic stimulation of $\Theta$-burst type applied to layer IV of the cortex. An example is shown in Figure 6. The application of BDNF did not significantly change layer II/III field potentials evoked by test stimulation of layer IV (Fig. 6Ab). After tetanic stimulation of layer IV, however, the postsynaptic component of responses was enhanced markedly (Fig. 6Ac), and this enhancement lasted until the end of recordings ( $30 \mathrm{~min}$ after tetanus) (Fig. 6B). The mean amplitudes of the postsynaptic component for 16 slices were plotted against time in Figure $7 B$. The mean value $25-30$ min after tetanus was $123.2 \pm 2.9 \%$ (SEM) of the control (Fig. 8, second column from left). Without BDNF on the other hand, tetanic stimulation of the same parameters induced a significant but weak LTP of layer II/III responses (Fig. 7 $A$ ). The mean value $25-30$ min after tetanus was $107.8 \pm 1.8 \%$ of the control (Fig. 8, left column). Such a small magnitude of LTP was reported to be induced in the visual cortex of rats without any antagonist for GABA receptors (Haruta et al., 1994). The difference in the mean value for 25-30 min after tetanus between slices without and with BDNF was statistically significant (ANOVA;

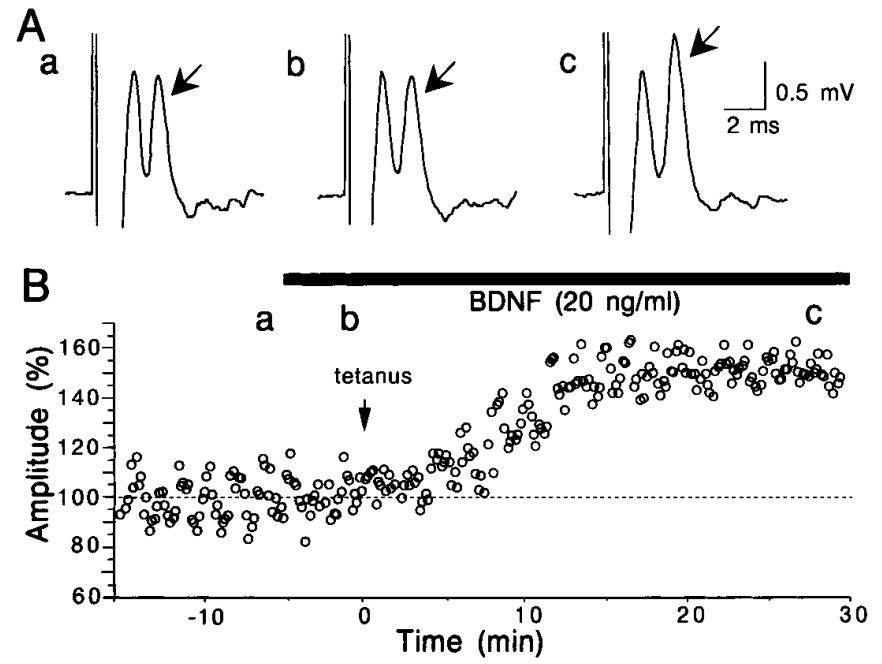

Figure 6. Enhancement of LTP by BDNF. $A$, Examples of layer II/III field responses to test stimulation of layer IV, recorded at the time points indicated by corresponding letters in $B$. Other conventions are the same as in Figure $2 A$. $B$, Time course of the amplitude of postsynaptic component of responses to test stimulation of layer IV. Tetanic stimulation was given to layer IV at the time 0 , indicated by arrow. The amplitude of responses is calculated as the percentage of the mean of 60 responses before the application of BDNF.

$p<0.0001)$. To test the possibility that a contaminant in the vehicle solution might be responsible for such an enhancing action of BDNF, the same procedures as in the BDNF application were repeated with heat-inactivated BDNF. LTP of the magnitude similar to that without BDNF was induced after tetanic stimulation (Fig. 8, third column from left). Also, NT-3 and NGF at the concentration of $20 \mathrm{ng} / \mathrm{ml}$ had no facilitatory effect (Fig. 8, second from right and far right columns). Finally, we tested whether the application of TrkB-IgG or K252a itself could affect the induction of LTP and then whether they could block the enhancing effect of BDNF on LTP. In 11 of the 13 slices that had been incubated with TrkB-IgG, LTP was not induced by tetanic stimulation of layer IV (Fig. 7E; also see Fig. 8, fourth column from left). In 14 of the 15 slices tested with K252a, LTP was not induced by tetanic stimulation of layer IV (Fig. 7C; also see Fig. 8, sixth column from left). In another 13 slices that had been incubated with TrkB-IgG, tetanic stimulation was given to layer IV during the BDNF application, but it turned out to be ineffective (Fig. $7 F$; also see Fig. 8, fifth column from left). In 11 of the 14 slices to which BDNF was coapplied with K252a, tetanic stimulation was again ineffective in inducing LTP (Fig. 7D; also see Fig. 8, third column from right). These results suggest that the enhancement of LTP by BDNF may be mediated through TrkB receptors, and endogenous BDNF or another endogenous TrkB ligand may play a role in LTP in the physiological condition.

\section{DISCUSSION}

\section{Long-lasting potentiation of responses by the high dose of BDNF}

In the present study we found that BDNF at the concentration of $200 \mathrm{ng} / \mathrm{ml}$ potentiated layer II/III responses to test stimulation of layer IV in most cases, and this potentiation lasted for at least 30 min after cessation of its application. Furthermore, this action of BDNF was blocked by TrkB-IgG, which competes with TrkB receptors for binding $\mathrm{BDNF}$, and by $\mathrm{K} 252 \mathrm{a}$, which inhibits recep- 
A
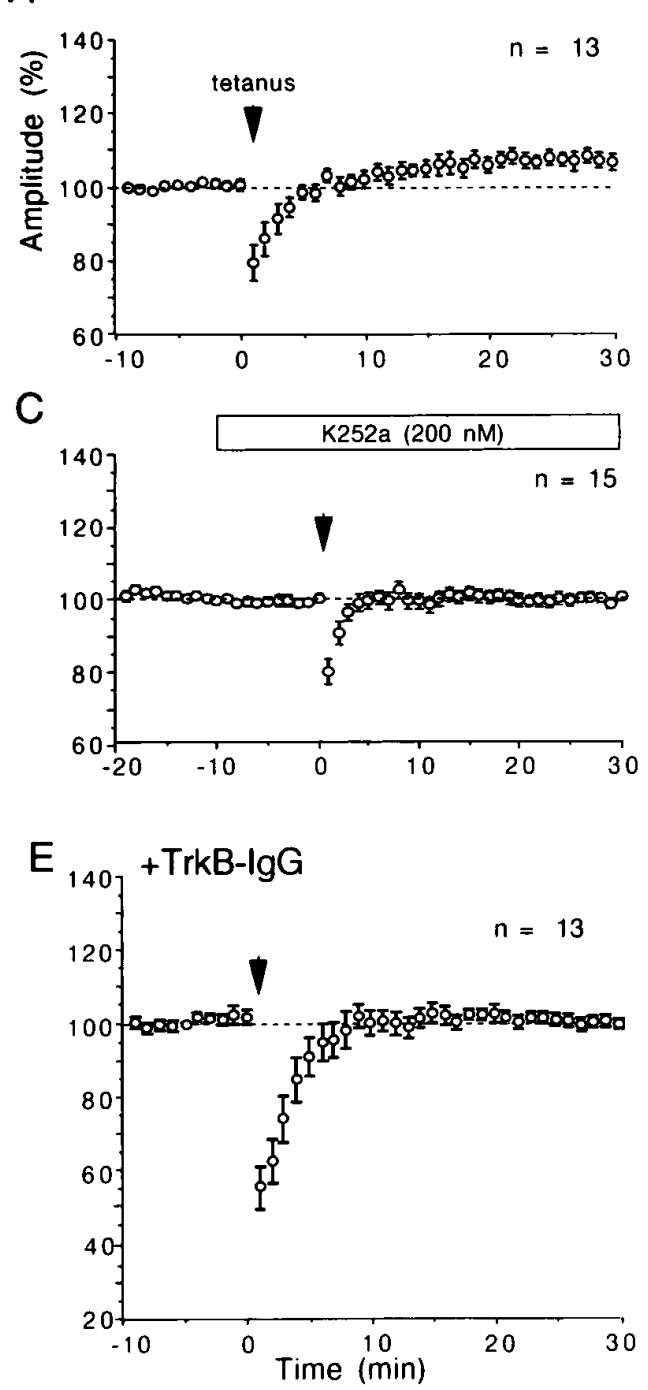

B

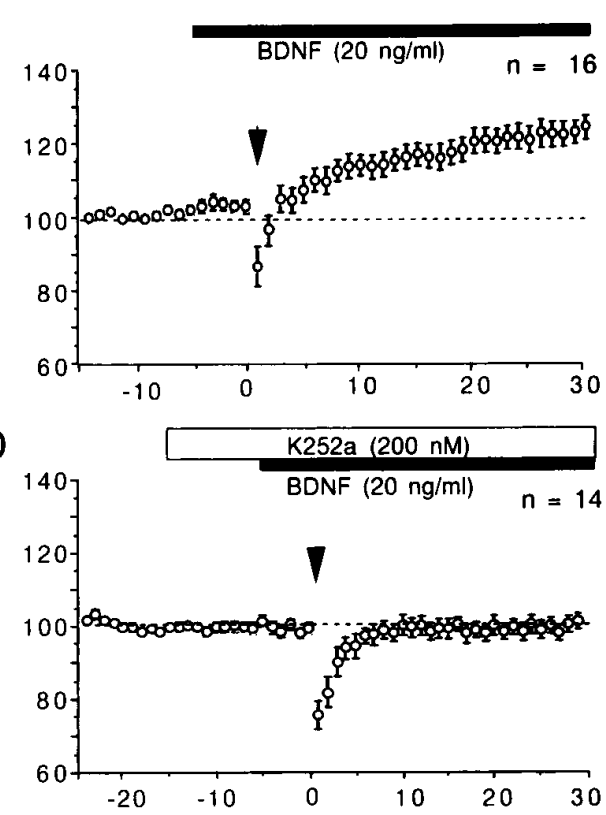

$\mathrm{F}$

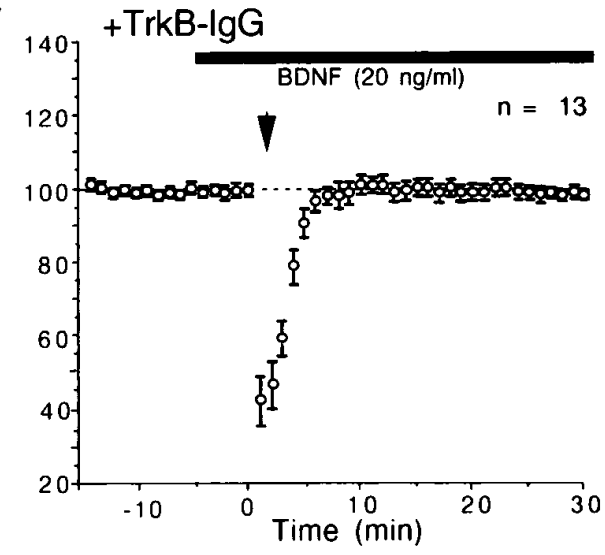

Figure 7. Time courses of mean amplitude of field responses after tetanic stimulation with or without BDNF, K252a, and TrkB-IgG. Vertical bars indicate twice the SEM for the same group of slices. Circles without vertical bars indicate that the value of SEM was smaller than that of radius. $A$, Tetanic stimulation was applied to layer IV of the cortex without any drug at the time point indicated by arrow. $B, C, D$, and $F$, Time courses of amplitude of responses after tetanus with BDNF and K252a, as indicated by horizontal bars. E, Time course of amplitude of responses after tetanus. In $E$ and $F$, slices were preincubated with TrkB-IgG. For each slice, the mean of six consecutive responses was calculated as percentage of that of 60 responses just before the application of $\operatorname{BDNF}(B, F)$, $\mathrm{K} 252 \mathrm{a}(C, D)$, or tetanic stimulation $(A, E)$. tor tyrosine kinases. These findings seem generally consistent with a previous study using hippocampal slices, although BDNF at the concentration as low as $20 \mathrm{ng} / \mathrm{ml}$ was reported to be effective (Kang and Schuman, 1995). The difference in the effective concentration of BDNF between the present and previous results may be attributable to a regional difference in density of TrkB. Hippocampus is known to express TrkB with the highest density in the brain, although visual cortex also expresses it densely (Klein et al., 1990; Merlio et al., 1992; Schoups et al., 1995; Cabelli et al., 1996). Recently, however, Figurov et al. (1996) reported that BDNF at $2 \mathrm{~nm}$ (corresponding to $\sim 100$ $\mathrm{ng} / \mathrm{ml}$ ) did not affect basal synaptic transmission elicited by lowfrequency stimulation ( 1 pulse/min) in the CA1 area of hippocampal slices. This discrepancy may be attributable to a difference in types of recording chambers, submerged and interface types, and/or in rates of perfusion of the medium, as discussed below.

\section{Rapid penetration of BDNF into slices}

Recently, Patterson et al. (1996) reported that exogenously applied BDNF at $100 \mathrm{ng} / \mathrm{ml}$ could penetrate only $\sim 20 \mu \mathrm{m}$ from the surface into hippocampal slices, even after $90 \mathrm{~min}$ of incubation. In the present study, we clearly demonstrated that exogenous BDNF penetrated into the whole slice within 5 min after initia- tion of its application. This discrepancy may be accounted for by the two differences in experimental conditions between their study and ours. In their study, hippocampal slices in an interface chamber were incubated for a given period with the medium containing BDNF. In the present study, on the other hand, BDNF was applied to submerged slices through the medium, which flowed continuously at the rate of $200 \mathrm{ml} / \mathrm{hr}$. In this context it is to be noted that two other studies reporting the rapid potentiating effects of BDNF with onset latency of $\sim 5-15 \mathrm{~min}$ on synaptic transmission in hippocampus and visual cortex also used slices that were submerged in a stream of the medium at a flow rate of 250 and $120 \mathrm{ml} / \mathrm{hr}$, respectively (Kang and Schuman, 1995; Carmignoto et al., 1997). Thus, BDNF might penetrate more rapidly into submerged slices that were exposed to continuous flow of the medium containing it than into slices that were incubated with it in an interface chamber. The other point to be noted is a structural difference. Visual cortical slices from young rats might be more permeable to BDNF than hippocampal slices from knockout mice that were used by Patterson et al. (1996).

\section{Enhancing action of BDNF on LTP}

In the present study we found that BDNF at $20 \mathrm{ng} / \mathrm{ml}$ enhanced the magnitude of LTP induced by tetanic stimulation of layer IV. 
Figure 8. Ratio of the amplitude of responses 25-30 min after tetanus to that of control responses. Ordinate represents the ratio of mean amplitude of the postsynaptic component of responses calculated from 30 consecutive responses for 25-30 min after tetanus to that of another 60 responses just before tetanus. Short horizontal bars and vertical bars represent means and twice the SEM for the same group of slices, respectively. The number of slices used for each test is shown at the top of each column. tet., Tetanic stimulation; inact. $B D N F$, inactivated BDNF.

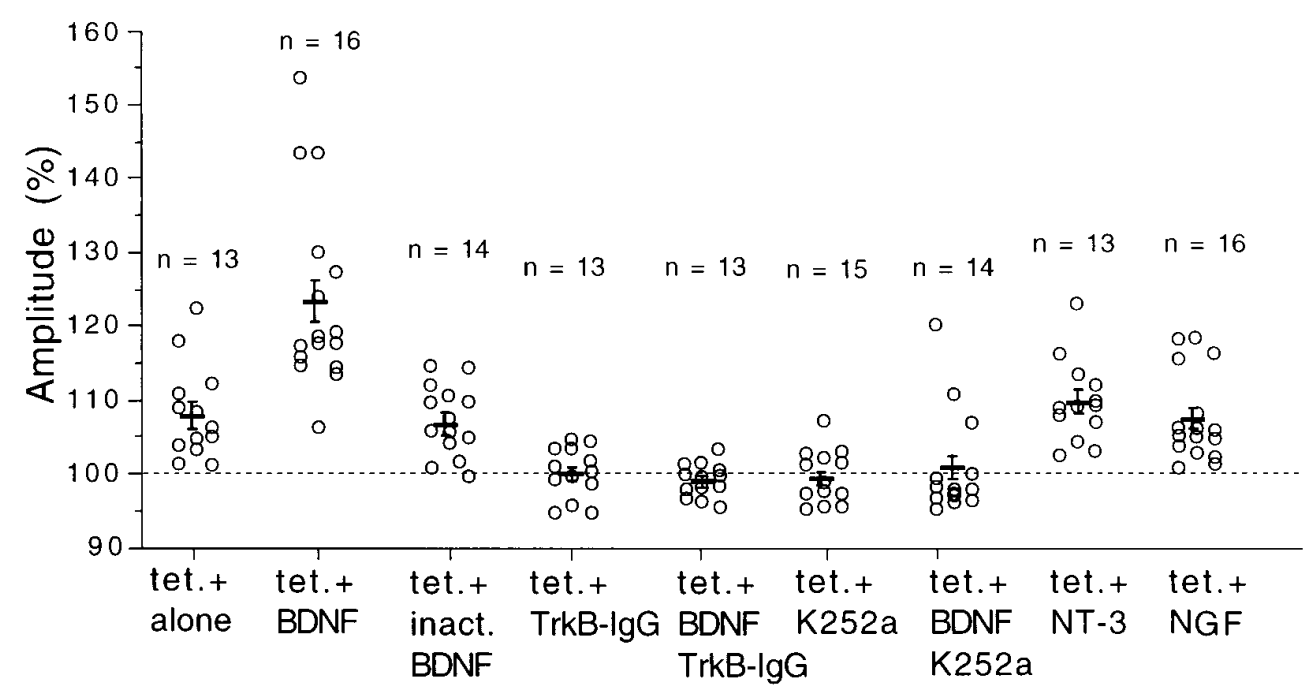

myocytes and spinal neurons (Lohof et al., 1993). In line with these findings, previous studies demonstrated that mRNA encoding TrkA, the high-affinity receptor for NGF, is confined to a few dispersed populations of cholinergic neurons in the basal forebrain and brain stem and not found in the cerebral cortex, including visual cortex (Merlio et al., 1992; Gibbs and Pfaff, 1994).

With respect to NT-3, previous studies using cell culture preparations of neurons and myocytes of Xenopus and of somatosensory cortical neurons of rats reported that this neurotrophin had potentiating effects on synaptic activity (Ip et al., 1993; Lohof et al., 1993; Kim et al., 1994, Wang et al., 1995). Using hippocampal slices, Kang and Schuman (1995) also reported that NT-3 enhanced synaptic transmission as BDNF did. On the other hand, Figurov et al. (1996) reported that NT-3 did not promote the induction of LTP in hippocampal slices prepared from young (postnatal day 12-13) rats, although BDNF did. In this context it is to be noted that NT-3 and NGF were found to be ineffective in modulating the formation of ocular dominance columns in kitten visual cortex, whereas BDNF was effective (Cabelli et al., 1995). Thus, actions of NT-3 seem inconsistent among species of animals and neural structures.

\section{Relevance to plasticity of the visual system}

The enhancement of LTP by BDNF seems to make sense in the light of recent findings of developmental plasticity of function and structure of visual cortex. The formation or segregation of ocular dominance columns in the visual cortex of kittens is suggested to be dependent on processes of consolidation of core axon terminals or retraction of exuberant terminals (Callaway and Katz, 1992; Antonini and Stryker, 1993). This suggestion seems to be consistent with the recent observations that the column formation in the visual cortex is impaired by the application of BDNF (Cabelli et al., 1995; Hata et al., 1996), because BDNF is known to increase their branching of axon terminals (Cohen-Cory and Fraser, 1995). It is postulated that the branching processes during the formation of ocular dominance columns may be related to LTP of active, core synapses (Tsumoto, 1992; Singer, 1995). Recently it has been suggested in hippocampus that BDNF stimulates the synthesis of proteins for expression of LTP at or near activated synapses (Kang and Schuman, 1996). Thus, the longlasting potentiation of active synapses by BDNF may lead to expansion of axon terminals or dendrites through the protein hippocampus (Kang and Schuman, 1995; Figurov et al., 1996) and it did not change synaptic activity in coculture preparations of 
synthesis. Therefore, it seems reasonable to assume that endogenous BDNF may play a role in activity-dependent modulation of synaptic connections in the developing visual cortex, as suggested previously (Castrén et al., 1992b; Bozzi et al., 1995; Cabelli et al., 1995; Galuske et al., 1996; Hata et al., 1996; McAllister et al., 1996).

Recently Katz and his associates reported that another endogenous ligand for TrkB, NT-4, has an antagonizing action on visual deprivation-induced atrophy of lateral geniculate neurons (Riddle et al., 1995) and a facilitatory action on dendritic growth of some cortical neurons (McAllister et al., 1995). In the present study we did not test NT-4, and thus we could not determine whether the two types of endogenous TrkB ligands have differential actions on cortical synaptic transmission. In any case, the present result that the application of TrkB-IgG prevented LTP from being generated by tetanic stimulation suggests that BDNF and/or NT-4 are normally present in limited amounts and may facilitate potentiation or consolidation of active synapses in the developing visual cortex.

\section{REFERENCES}

Akaneya Y, Tsumoto T, Hatanaka H (1996) BDNF is involved in expression of long-term potentiation in visual cortex of young rats. Neurosci Res [Suppl] 20:S160.

Antonini A, Stryker MP (1993) Development of individual geniculocortical arbors in the cat striate cortex and effects of binocular impulse blockade. J Neurosci 13:3549-3573.

Barde Y-A (1989) Trophic factors and neuronal survival. Neuron 2:1525-1534.

Bonhoeffer T (1996) Neurotrophins and activity-dependent development of the neocortex. Curr Opin Neurobiol 6:119-126.

Bothwell M (1995) Functional interactions of neurotrophin and neurotrophin receptors. Annu Rev Neurosci 18:223-253.

Bozzi Y, Pizzorusso T, Cremisi F, Rossi FM, Barsacchi G, Maffei L (1995) Monocular deprivation decreases the expression of messenger RNA for brain-derived neurotrophic factor in the rat visual cortex. Neuroscience 69:1133-1144.

Cabelli RJ, Hohn A, Shatz CJ (1995) Inhibition of ocular dominance column formation by infusion of NT-4/5 or BDNF. Science 267:1662-1666.

Cabelli RJ, Allendoerfer KL, Radeke MJ, Welcher AA, Feinstein SC, Shatz CJ (1996) Changing patterns of expression and subcellular localization of TrkB in the developing visual system. J Neurosci 16:7965-7980.

Callaway EM, Katz LC (1992) Development of axonal arbors of layer 4 spiny neurons in cat striate cortex. J Neurosci 12:570-582.

Carmignoto G, Canella R, Candeo P, Comelli MC, Maffei L (1993) Effects of nerve growth factor on neuronal plasticity of the kitten visual cortex. J Physiol (Lond) 464:343-360.

Carmignoto G, Pizzorusso T, Tia S, Vicini S (1997) Brain-derived neurotrophic factor and nerve growth factor potentiate excitatory synaptic transmission in the rat visual cortex. J Physiol (Lond) 498:153-164.

Castrén E, Pitkänen M, Sirviö J, Parsadanian A, Lindholm D, Thoenen H, Riekkinen PJ (1992a) The induction of LTP increases BDNF and NGF mRNA but decreases NT-3 mRNA in the dentate gyrus. NeuroReport 4:895-898.

Castrén E, Zafra F, Thoenen H, Lindholm D (1992b) Light regulates expression of brain-derived neurotrophic factor mRNA in rat visual cortex. Proc Natl Acad Sci USA 89:9444-9448.

Cohen-Cory S, Fraser SE (1995) Effects of brain-derived neurotrophic factor on optic axon branching and remodelling in vivo. Nature 378:192-195.

Davies AM (1994) The role of neurotrophins in the developing nervous system. J Neurobiol 25:1334-1348.

Figurov A, Pozzo-Miller LD, Olafsson P, Wang T, Lu B (1996) Regulation of synaptic responses to high-frequency stimulation and LTP by neurotrophins in the hippocampus. Nature 381:706-709.

Galuske RAW, Kim D-S, Castrén E, Thoenen H, Singer W (1996) Brain-derived neurotrophic factor reverses experience-dependent synaptic modifications in kitten visual cortex. Eur $\mathbf{J}$ Neurosci 8:1554-1559.

Gibbs RB, Pfaff DW (1994) In situ hybridization detection of trkA mRNA in brain: distribution, colocalization with $\mathrm{p} 75^{\mathrm{NGFR}}$ and upregulation by nerve growth factor. J Comp Neurol 341:324-339.

Haruta H, Kamishita T, Hicks TP, Takahashi MP, Tsumoto T (1994) Induction of LTD but not LTP through metabotropic glutamate receptors in visual cortex. NeuroReport 5:1829-1832.

Hata Y, Katsuyama N, Fukuda M, Ohshima M, Tsumoto T, Hatanaka H (1996) Brain-derived neurotrophic factor disrupts effects of monocular deprivation in kitten visual cortex. Soc Neurosci Abstr 22:1728.

Ip NY, Li Y, Yancopoulos GD, Lindsay RM (1993) Cultured hippocampal neurons show responses to BDNF, NT-3, and NT-4, but not NGF. J Neurosci 13:3394-3405.

Kang H, Schuman EM (1995) Long-lasting neurotrophin-induced enhancement of synaptic transmission in the adult hippocampus. Science 267:1658-1662.

Kang H, Schuman EM (1996) A requirement for local protein synthesis in neurotrophin-induced hippocampal synaptic plasticity. Science 273:1402-1406.

Kase H, Iwahashi K, Matsuda Y (1986) K-252a, a potent inhibitor of protein kinase C from microbial origin. J Antibiol 39:1059-1065.

Kim HG, Wang T, Olafsson P, Lu B (1994) Neurotrophin 3 potentiates neuronal activity and inhibits $\gamma$-aminobutyratergic synaptic transmission in cortical neurons. Proc Natl Acad Sci USA 91:12341-12345.

Kimura F, Nishigori A, Shirokawa T, Tsumoto T (1989) Long-term potentiation and $N$-methyl-D-aspartate receptors in the visual cortex of young rat. J Physiol (Lond) 414:125-144.

Kirkwood A, Dudek SM, Gold JT, Aizeman CD, Bear MF (1993) Common forms of synaptic plasticity in the hippocampus and neocortex in vivo. Science 260:1518-1521.

Klein R, Martin-Zanca D, Barbacid M, Parada LF (1990) Expression of the tyrosine kinase receptor gene trk $\mathrm{B}$ is confined to the murine embryonic and adult nervous system. Development 109:845-850.

Knüsel B, Hefti F (1992) K-252 compounds: modulator of neurotrophin signal transduction. J Neurochem 59:1987-1996.

Koizumi S, Contreras ML, Matsuda Y, Hama T, Lazarovici P, Guroff G (1988) K-252a: a specific inhibitor of the action of nerve growth factor on PC12 cell. J Neurosci 8:715-721.

Korte M, Carroll P, Wolf E, Brem G, Thoenen H, Bonhoeffer T (1995) Hippocampal long-term potentiation is impaired in mice lacking brain-derived neurotrophic factor. Proc Natl Acad Sci USA 92:8856-8860.

Leßmann V, Kottmann K, Heumann R (1994) BDNF and NT-4/5 enhance glutamatergic synaptic transmission in cultured hippocampal neurones. NeuroReport 6:21-25.

Levi-Montalcini R (1987) The nerve growth factor: thirty-five years later. EMBO J 6:1145-1154.

Levine ES, Dreyfus CF, Black IB, Plummer MR (1995) Brain-derived neurotrophic factor rapidly enhances synaptic transmission in hippocampal neurons via postsynaptic tyrosine kinase receptor. Proc Natl Acad Sci USA 92:8074-8077.

Lewin GR, Barde Y-A (1996) Physiology of the neurotrophins. Annu Rev Neurosci 19:289-317.

Lohof AM, Ip NY, Poo M-M (1993) Potentiation of developing neuromuscular synapses by the neurotrophins NT-3 and BDNF. Nature 363:350-353.

Maffei L, Berardi N, Domenici L, Parisi V, Pizzorusso T (1992) Nerve growth factor (NGF) prevents the shift in ocular dominance distribution of visual cortical neurons in monocularly deprived rats. J Neurosci 12:4651-4662.

McAllister AK, Lo DC, Katz LC (1995) Neurotrophins regulate dendritic growth in developing visual cortex. Neuron 15:791-803.

McAllister AK, Katz LC, Lo DC (1996) Neurotrophin regulation of cortical dendritic growth requires activity. Neuron 17:1057-1064.

Merlio JP, Ernfors P, Jaber M, Persson H (1992) Molecular cloning of rat trkC and distribution of cells expressing messenger RNAs for members of the trk family in the rat central nervous system. Neuroscience 51:513-532.

Patterson SL, Grover LM, Schwartzkroin PA, Bothwell M (1992) Neurotrophin expression in rat hippocampal slices: a stimulus paradigm inducing LTP in CA1 evokes increases in BDNF and NT-3 mRNAs. Neuron 9:1081-1088.

Patterson SL, Abel T, Deuel TAS, Martin KC, Rose JC, Kandel ER 
(1996) Recombinant BDNF rescues deficits in basal synaptic transmission and hippocampal LTP in BDNF knockout mice. Neuron 16:1137-1145.

Riddle DR, Lo DC, Katz LC (1995) NT-4-mediated rescue of lateral geniculate neurons from effects of monocular deprivation. Nature 378:189-191.

Schoups AA, Elliott RC, Friedman WJ, Black IB (1995) NGF and BDNF are differentially modulated by visual experience in the developing geniculocortical pathway. Dev Brain Res 86:326-334.

Shelton DL, Sutherland J, Gripp J, Camerato T, Armanini MP, Phillips HS, Carroll K, Spencer SD, Levinson AD (1995) Human trks: molecular cloning, tissue distribution, and expression of extracellular domain immunoadhesions. J Neurosci 15:477-481.

Singer W (1995) Development and plasticity of cortical processing architectures. Science 270:758-764.
Stoop R, Poo M-M (1996) Synaptic modulation by neurotrophic factors: differential and synergistic effects of brain-derived neurotrophic factor and ciliary neurotrophic factor. J Neurosci 16:3256-3264.

Tanaka T, Saito H, Matsuki N (1997) Inhibition of GABA synaptic responses by brain-derived neurotrophic factor (BDNF) in rat hippocampus. J Neurosci 17:2959-2966.

Thoenen H (1995) Neurotrophins and neuronal plasticity. Science 270:593-598.

Tsumoto T (1992) Long-term potentiation and long-term depression in the neocortex. Prog Neurobiol 39:209-228.

Wang T, Xie K, Lu B (1995) Neurotrophins promote maturation of developing neuromuscular synapses. J Neurosci 15:4796-4805.

Yoshimura Y, Tsumoto T (1994) Dependence of LTP induction on postsynaptic depolarization: a perforated patch-clamp study in visual cortical slices of young rats. J Neurophysiol 71:1638-1645. 